\title{
Pharmacists' Perceptions of the Influence of Interactions with the Pharmaceutical Industry on Clinical Decision-Making
}

\author{
Aaron M Tejani, Peter Loewen, Richard Bachand, and Curtis K Harder
}

\begin{abstract}
Background: There is a paucity of literature examining the perceptions of Canadian pharmacists toward drug promotion by the pharmaceutical industry and pharmacist-industry interactions.

Objectives: To determine whether hospital pharmacists perceive their interactions with the pharmaceutical industry as influencing their clinical decision-making or that of their colleagues and whether hospital pharmacists perceive that interactions with the pharmaceutical industry create a conflict of interest.
\end{abstract}

Methods: A cross-sectional survey of the complete sample of hospital pharmacists practising in 3 large health authorities in a single Canadian province was conducted from February to April 2010.

Results: A total of 224 responses were received from the approximately 480 pharmacists in the target health authorities (response rate approximately 47\%). Fifty-eight percent of respondents (127/218) did not believe that information received at industry-sponsored events influenced their clinical decision-making. Most (142/163 [87\%]) disagreed that small gifts influenced their clinical decision-making, whereas responses were divided for large gifts. Respondents were also divided on the issue of whether their interactions created conflicts of interest, with most of those who had received gifts agreeing that large gifts would create a conflict of interest (134/163 [82\%]) whereas small gifts would not (100/163 [61\%]). There were positive correlations between respondents' beliefs about their own susceptibility to influence from sponsored events or receipt of small or large gifts and the susceptibility of others, but $22 \%$ of respondents (28/127) expressed a different perception about sponsored events, all believing themselves to be less influenced than their colleagues. Only 6\% (4/64) of those who received large gifts and $4 \%(5 / 142)$ of those who received small gifts and felt they were not influenced by these gifts reported that it was likely others would be influenced by the receipt of such gifts.

Conclusions: Most hospital pharmacists who responded to this survey had attended industry-sponsored events, and the majority felt that it did not influence their clinical decision-making, despite recognition that the information received is unbalanced. Respondents were divided on the notion of whether these interactions led to conflicts of interest. Respondents generally felt that large and small gifts had different effects on influence and conflict of interest.

Keywords: drug promotion, pharmaceutical industry, influence

\section{RÉSUMÉ}

Contexte : Il n'existe que très peu de documentation qui porte sur la perception des pharmaciens canadiens envers la promotion des médicaments par l'industrie pharmaceutique et leurs relations avec cette industrie.

Objectifs : Déterminer si les pharmaciens d'hôpitaux croient que leurs relations avec l'industrie pharmaceutique les influencent ou influencent leurs collègues dans leur prise de décision clinique et s'ils croient que les relations avec l'industrie pharmaceutique sont source de conflits d'intérêts.

Méthodes : Une enquête transversale auprès de l'ensemble des pharmaciens d'hôpitaux exerçant au sein de trois grandes régies de la santé dans une seule province canadienne a été réalisée entre février et avril 2010.

Résultats : En tout, on a obtenu 224 réponses des quelque 480 pharmaciens des régies de la santé visées (taux de réponse approximatif de $47 \%$ ). Cinquante-huit pour cent des répondants (127/218) ont affirmé ne pas croire que des informations obtenues au cours d'activités organisées par l'industrie aient une influence sur leur prise de décision clinique. La plupart (142/163 [87 \%]) ne croyaient pas que des cadeaux modestes puissent influencer leur prise de décision clinique, alors que les réponses étaient partagées pour ce qui est des cadeaux importants. Les répondants étaient aussi partagés sur la question à savoir si leurs relations étaient source de conflits d'intérêts. La majorité de ceux ayant reçu des cadeaux affirmaient que recevoir des cadeaux importants pourrait créer des conflits d'intérêts (134/163 [82\%]), mais que ça ne serait pas le cas avec des cadeaux modestes (100/163 [61\%]). On a remarqué des corrélations positives entre les croyances des répondants à propos de la possibilité qu'ils puissent eux-mêmes être influencés par les activités commanditées ou par des cadeaux importants ou modestes et la vulnérabilité des autres à être influencés dans une même situation. Mais $22 \%$ d'entre eux (28/127) ont indiqué avoir une perception différente en ce qui a trait aux activités organisées par l'industrie : ils croyaient tous être moins influencés que leurs collègues. Parmi les personnes qui ont répondu qu'elles ne croyaient pas avoir été influencées par des cadeaux perçus, seulement $6 \%(4 / 64)$ de celles ayant reçu des cadeaux importants et $4 \%$ (5/142) de celles ayant reçu des cadeaux modestes ont affirmé que les autres seraient probablement influencées par de tels cadeaux.

Conclusions : La plupart des pharmaciens ayant répondu à cette enquête ont participé à des activités organisées par l'industrie. La majorité d'entre eux ne croyaient pas que cela ait eu une influence sur leur prise de décision 
Can J Hosp Pharm. 2015;68(5):378-85

\section{INTRODUCTION}

$\mathrm{D}$

rug promotion directed toward health care professionals is one method of marketing used by the pharmaceutical industry. However, the accuracy or usefulness of the information in scientific documents provided by industry representatives in promotional encounters with clinicians is questionable. Ziegler ${ }^{1}$ reported that $11 \%$ of statements made by pharmaceutical representatives in 13 presentations were inaccurate, with a tendency for the inaccurate statements to be favourable toward the drug being promoted. Mintzes and others ${ }^{2}$ found that pharmaceutical sales representatives routinely de-emphasized the serious risks of drugs. These findings would be problematic if such promotion leads to inappropriate or suboptimal prescribing for individual patients, and evidence suggests that such is indeed the case. Physicians' interaction with sales representatives from pharmaceutical companies is associated with alterations in prescribing behaviours. For example, a systematic review identified several effects of physician-industry interaction, including increased requests for representatives' products to be added to formulary, despite most of the requested products having little or no therapeutic advantage over existing drugs; other effects identified by the systematic review were increased cost of prescribed drugs, irrational prescribing, rapidity of prescribing new drugs, and decreased prescribing of generic drugs. ${ }^{3}$ Other types of interactions, such as receiving gifts or meals, attending sponsored educational events, receiving samples, receiving sponsorship for continuing education, or receiving research funding all had positive effects on physicians' beliefs and perceptions about the associated drug products. ${ }^{3-7} \mathrm{~A}$ more recent systematic review confirmed most of these findings. Spurling and others ${ }^{8}$ reported that exposure to pharmaceutical industry marketing led to increased prescribing, lower-quality prescribing, and higher health care costs; however, in some of the studies, pharmaceutical industry marketing had no impact on drug therapy for patients. These authors found no evidence that exposure to marketing improves any facet of prescribing. ${ }^{8}$

Most pharmacists support the practice of evidence-based medicine and believe that they have an obligation to make drug recommendations based on the best evidence available.' Nonetheless, $45 \%$ of practising pharmacists said that they lacked clinique, et ce, bien qu'ils aient reconnu que les informations reçues n'étaient pas impartiales. Les répondants étaient partagés sur la question à savoir si ces relations étaient ou non source de conflits d'intérêts. En général, ils croyaient que l'importance du cadeau influençait différemment les gens et qu'elle influait sur l'existence ou non d'un conflit d'intérêts.

Mots clés : promotion des médicaments, industrie pharmaceutique, influence the time to perform the literature searches required to make evidence-based decisions, and $11 \%$ stated that they did not have the resources to do so. ${ }^{9}$ Hence, pharmacists often rely on summaries of evidence to obtain drug information and make therapeutic decisions. ${ }^{9}$ Time constraints may increase the vulnerability of pharmacists to the ready accessibility of pharmaceutical industry representatives, who provide information in a quick and simple manner, and to readily available pharmaceutical industry-sponsored education events. Reliance on these sources of information exposes pharmacists to unknown biases, some of which may result in undesirable behaviours similar to those of physicians. Some of these behaviours may be detrimental to the fulfillment of pharmacists' professional responsibilities to their patients and to society and may also be inconsistent with evidence-based practice.

Compared with the situation for physicians, research on how drug promotion by the pharmaceutical industry affects pharmacists is scarce. A survey of US pharmacists found a generally positive perception of the pharmaceutical industry and identified the beliefs that sales representatives are valuable to pharmacists and that they provide useful drug information to pharmacists; however, there was also recognition that industry representatives provide pharmacists with gifts that have nothing to do with patient care. ${ }^{10}$

Similarly, there is a paucity of literature examining the perceptions of Canadian pharmacists toward drug promotion by the pharmaceutical industry or pharmacist-industry interactions. It is not known whether the perceptions of Canadian pharmacists differ from those of their US counterparts; however, such differences are possible, given that the 2 countries have different regulations regarding drug promotion and given that the marketplace for drugs is much larger in the United States than in Canada. ${ }^{2}$ This study was undertaken to examine these perceptions among pharmacists practising in 3 large health authorities in Canada.

The study aimed to determine the beliefs of hospital pharmacists with regard to interactions with the pharmaceutical industry. The specific objective was to assess whether Canadian hospital pharmacists perceive that interactions with the pharmaceutical industry (in the form of gifts, sponsored continuing education, and advertising) influence their clinical 
decision-making or that of their colleagues and whether pharmacists perceive that interactions with the pharmaceutical industry create a conflict of interest.

\section{METHODS}

This cross-sectional survey involved the complete sample of approximately 480 pharmacists practising in 3 large multisite health authorities in a single Canadian province. The health authorities (Fraser Health, Vancouver Coastal Health, and Island Health) were all located in and accounted for $100 \%$ of the hospital pharmacists in southwestern British Columbia, Canada, the most populous area of the province. The study protocol received ethics approval from the research ethics boards of the 3 health authorities before commencement.

The investigators developed a study-specific online survey, which was pilot-tested by 3 practising pharmacists for readability, logical flow, and face validity. The investigators determined that sponsorship of continuing education events and other activities, acceptance of gifts, acceptance of free drug samples, and associated influence and conflict of interest would be suitable themes to explore. Selection of the survey items was based on personal experience (as discussed among the 4 investigators) and a scan of the literature concerning the influence of promotional activity, drug promotion more generally, and issues related to self-other biases (i.e., personal beliefs about influence on oneself versus the same influence upon others). ${ }^{11}$ Specific questions related to the survey items were developed through discussion and consensus. After refinement of the survey, direct supervisors within each health authority contacted their own staff members by e-mail, inviting them to complete the online survey. Two weeks after the initial invitation, a reminder to complete the survey was sent by the same method. The initial invitation was sent in February 2010, and responses were accepted until April 2010.

Respondents were asked to provide basic demographic information and then to answer questions about their beliefs, activities, and perceptions relating to interactions with the pharmaceutical industry using predominantly Likert-type scales (see Appendix 1, available at www.cjhp-online.ca/index.php/ cjhp/issue/view/111/showToc). No personal information that could be used to identify respondents was collected. The survey tool had IP identity-tracking functionality, designed to prevent repeat completion of the questionnaire by the same respondent; however, this functionality could not prevent a respondent from completing the survey more than once from different computers.

\section{Statistical Analysis}

The primary research question was "Do Canadian hospital pharmacists perceive their interactions with the pharmaceutical industry (attending sponsored continuing education, receiving gifts) to have an influence on their clinical decision-making or that of their colleagues?" The 2 populations for the primary analysis were respondents who answered "Yes" to 2 specific questions in the survey: "Have you ever accepted meals or attended CME [continuing medical education] lunch/dinner events that were sponsored by pharmaceutical companies?" and "Have you ever received gifts from pharmaceutical companies?" Separate analyses were conducted for these 2 populations. For the purposes of this study, and specifically this article, the activities described by these 2 questions collectively constituted "interaction with the pharmaceutical industry". Those who responded "yes" to the second of these questions were also asked to specify the size of the gifts: "small" or "large." The size categories were not defined. Rather, examples were provided: "pens, notepads, cups" for small gifts and "trips, tickets to events, golf" for large gifts. Survey results unrelated to the primary question of whether pharmacists perceive their interactions with the pharmaceutical industry to have an influence on their or their colleagues' clinical decision-making are not presented or discussed in this paper. Other survey questions addressed issues such as free drug samples and pharmaceutical industry funding of university faculties of pharmacy and professional organizations, and the data from these questions will be analyzed and published separately in future papers.

For each of the 2 types of industry interaction, correlation analyses were performed to ascertain whether respondents' beliefs about their own susceptibility to influence were consistent with their beliefs about their colleagues' susceptibility.

The secondary question under consideration for the current study was "Do pharmacists perceive that interactions with the pharmaceutical industry create a conflict of interest?" All of the respondents who answered survey questions relevant to this topic (i.e., questions concerning whether these interactions influence their colleagues' practice) were included in this analysis, regardless of whether they declared having interactions with the pharmaceutical industry. Descriptive statistics were generated for these items.

The Spearman rho was calculated for correlations of responses based on Likert-type scales. Conventional definitions of strength of correlation were used for statistically significant Pearson correlation coefficients $(r<0.3$, weak; $r=0.3-0.7$, moderate; $r>0.7$, strong). SPSS version 20 (IBM, Armonk, New York) was used for all statistical analyses.

\section{RESULTS}

The number of pharmacists who received the initial invitation to participate was approximately 480 , which represents an essentially complete sample of pharmacists within the acute, ambulatory, and residential care hospital systems in the geographic area. Of these, 224 provided responses, for a $47 \%$ response rate (see Table 1). The authors did not have direct access to individual pharmacists' contact information; instead, they 
Table 1. Characteristics of Study Participants

\begin{tabular}{|c|c|}
\hline Characteristic & o) of Respondents \\
\hline Years practising pharmacy & $(n=222)$ \\
\hline $0-5$ & $49(22.1)$ \\
\hline $6-10$ & $29(13.1)$ \\
\hline$\geq 11$ & $144 \quad(64.9)$ \\
\hline Primary professional role & $(n=222)$ \\
\hline Administrator or supervisor & $46(20.7)$ \\
\hline $\begin{array}{l}\text { Pharmacist with primarily drug } \\
\text { distribution responsibilities } \\
(<20 \% \text { clinical) }\end{array}$ & $13 \quad(5.9)$ \\
\hline $\begin{array}{l}\text { Pharmacist with drug distribution } \\
\text { and clinical responsibilities }\end{array}$ & 75 (33.8) \\
\hline $\begin{array}{l}\text { Pharmacist with primarily clinical } \\
\text { responsibilities (<20\% drug distribution) }\end{array}$ & 45 (20.3) \\
\hline $\begin{array}{l}\text { Pharmacist with only clinical } \\
\text { responsibilities (e.g., patient care, } \\
\text { teaching) }\end{array}$ & 43 (19.4) \\
\hline Type of practice site & $(n=221)$ \\
\hline Tertiary acute care facility & 132 (59.7) \\
\hline $\begin{array}{l}\text { Community facility with acute } \\
\text { and residential care }\end{array}$ & 66 (29.9) \\
\hline Residential care facility & (3.6) \\
\hline Community care & $15 \quad(6.8)$ \\
\hline Time spent doing patient care & $(n=222)$ \\
\hline $0 \%$ & $24(10.8)$ \\
\hline $1 \%-20 \%$ & $43(19.4)$ \\
\hline $21 \%-50 \%$ & $49(22.1)$ \\
\hline$>50 \%$ & $106 \quad(47.7)$ \\
\hline Highest level of education & $(n=222)$ \\
\hline Bachelor's degree & 51 (23.0) \\
\hline Pharmacy practice residency & 101 (45.5) \\
\hline PharmD, Master's, and/or PhD & $70 \quad(31.5)$ \\
\hline
\end{tabular}

relied on pharmacists' direct supervisors to convey the e-mail invitation to staff members and ascertained from the supervisors an approximate count of pharmacists to whom the invitation was distributed. As such, the exact number of pharmacists who received the survey is not known and the response rate is an approximation. Three of the responses were excluded because the respondent did not answer the question about accepting meals or attending sponsored events, which left 221 surveys for analysis of the primary outcome (respondents' perceptions of influence of interactions with the pharmaceutical industry on clinical decision-making). In total, 222 respondents met the criteria for inclusion in the secondary analysis (related to perceptions of conflict of interest).

The pharmacists' practices were approximately two-thirds urban and one-third rural, and three-quarters inpatient and onequarter ambulatory in nature. In accordance with the study protocol, the 218 participants who reported that they had attended meals or continuing education events were included in the primary analysis of effects of attending industry-sponsored events, and 163 of these were included in the analysis of the effects of receiving gifts from the pharmaceutical industry. Demographic characteristics of the respondents are presented in
Table 1 . The typical respondent had been practising for more than 11 years, worked in a tertiary care facility, had a mix of clinical and distribution-related responsibilities with more than $50 \%$ of time devoted to direct patient care, and had residency or higher-level training.

For the primary research question, $37 \%$ of respondents ( 81 of the 218 who reported attending industry-sponsored events) reported that interactions with the pharmaceutical industry influenced their practice and how they made drug recommendations (Table 2). However, a majority (58\% [127/218]) indicated that attending industry sponsored events did not influence their recommendations. Of these respondents who reported that they had not been influenced, only $22 \%(28 / 127)$ thought that others were influenced (Table 2). When asked whether information at industry-sponsored continuing education events is balanced, 79\% (175/222) disagreed or strongly disagreed. The majority (87\% [142/163]) of respondents felt that small gifts did not influence their practice, and of those, only $4 \%$ (5/142) felt that small gifts influenced other pharmacists (Table $2)$. In contrast, only 39\% (64/163) of respondents thought that their practice was not influenced by large gifts, and 6\% of those (4/64) thought that others would be influenced by large gifts.

With respect to conflict of interest, respondents were divided over whether attendance at industry-sponsored continuing education events creates an actual or perceived conflict of interest (Table 2). Of respondents who had previously received a gift of any size, only 33\% (53/163) perceived a small gift as a conflict of interest, whereas $82 \%(134 / 163)$ perceived a large gift as a conflict of interest (Table 2). Among pharmacists who had never received a gift of any size, a small gift was considered a conflict of interest by $50 \%$ (29/58), and a large gift by $84 \%$ (49/58) (Table 2).

Respondents were about evenly split in terms of agreement with the statement "My relationship to the pharmaceutical industry promotes my professionalism and helps me care for my patients": 44\% (96/220) agreed or somewhat disagreed whereas $37 \%(81 / 220)$ agreed or somewhat agreed.

Although overall there were moderate or strong correlations between respondents' beliefs about their own susceptibility to influence from sponsored continuing education events or receipt of small or large gifts and the susceptibility of others (Table 3), $22 \%(28 / 127)$ of respondents expressed a discordant perception about sponsored attendance at continuing education events: all of these respondents believed themselves to be less influenced than their colleagues by such attendance. This effect was much less evident for receipt of gifts, with 6\% (4/64) of recipients of large gifts and 4\% (5/142) of recipients of small gifts reporting that they were not influenced but believed that others were. For both categories (attendance at events, receipt of gifts), no respondents expressed the opposite discordant belief, that they were more susceptible than their colleagues. 
Table 2. Responses to Selected Survey Questions

Question

No. $(\%)$ of

Respondents*

Topic area: Do pharmacists perceive attending sponsored CME to have

an influence on their clinical decision-making or that of their colleagues?

Have you ever accepted meals or attended CME lunch/dinner events that were sponsored by

pharmaceutical companies?

Yes

$218 / 221$

$3 / 221$

(99)

No

$127 / 218(58)$

drug recommendations

Disagree/somewhat disagree

$81 / 218 \quad(37)$

The information provided at those events influences other pharmacists' practice and how they

make recommendations

Disagree/somewhat disagree

$50 / 127 \quad(39)$

Agree/somewhat agree

$28 / 127$

Topic area: Do pharmacists perceive receiving gifts to have an influence on their clinical

decision-making or that of their colleagues?

Large gifts influence my practice and how I make recommendations

Disagree/somewhat disagree $\quad 64 / 163$

Agree/somewhat agree

Small gifts influence my practice and how I make recommendations

Disagree/somewhat disagree

Agree/somewhat agree

$16 / 163$

Of those who disagree or somewhat disagree to being influenced

Large gifts influence other pharmacists' practice and how they make recommendations Disagree/somewhat disagree

Agree/somewhat agree

Small gifts influence other pharmacists' practice and how they make recommendations

Disagree/somewhat disagree $\quad 92 / 142 \quad(65)$

Agree/somewhat agree

$5 / 142$

Of those who agree or somewhat agree to being influenced

Large gifts influence other pharmacists' practice and how they make recommendations Disagree/somewhat disagree

Agree/somewhat agree

Small gifts influence other pharmacists' practice and how they make recommendations

Disagree/somewhat disagree

$0 / 16$

Agree/somewhat agree

$14 / 16$

Topic area: Do pharmacists perceive that attending events creates

conflict of interest?

Have you ever accepted meals or attended CME lunch/dinner events that were sponsored

by pharmaceutical companies?

No

$3 / 221 \quad(1)$

Yes

$218 / 221$

Among those responding "yes": disagree or somewhat disagree that attending

$102 / 218$

such events is a perceived or actual conflict of interest

Topic area: Do pharmacists perceive that receiving gifts creates conflict of interest?

Have you ever received gifts from pharmaceutical companies?

Yes

$163 / 222$

No

$58 / 222$

Accepting small gifts is a perceived or actual conflict of interest

Of those who received gifts

Disagree/somewhat disagree $\quad 100 / 163$

Agree/somewhat agree

$53 / 163$

Of those who did not receive gifts

Disagree/somewhat disagree

Agree/somewhat agree

$29 / 58 \quad(50)$

Accepting large gifts is a perceived or actual conflict of interest

Of those who received gifts

Disagree/somewhat disagree

$19 / 163 \quad(12)$

Agree/somewhat agree

$134 / 163$

Of those who did not receive gifts

Disagree/somewhat disagree

$6 / 58 \quad(10)$

Agree/somewhat agree

$49 / 58$

$\mathrm{CME}=$ continuing medical education

*The "I do not know" responses are not presented in this table. Therefore, the sum of numerators for any given question

is smaller than the corresponding denominator. 


\section{Table 3. Correlations between Respondents' Perceptions of Influences on Their Own Practice and That of Other Pharmacists}

\begin{tabular}{|c|c|c|c|c|}
\hline Factor 1* & Factor 2* & Pearson $r \dagger$ & $p$ Value & $\begin{array}{l}\text { Strength of } \\
\text { Correlation }\end{array}$ \\
\hline $\begin{array}{l}\text { The information provided at } \\
\text { sponsored CE events has an } \\
\text { influence on my practice and how } \\
\text { I make drug recommendations. }\end{array}$ & $\begin{array}{l}\text { The information provided at sponsored } \\
\text { CE events influences other } \\
\text { pharmacists' practice and how they } \\
\text { make drug recommendations. }\end{array}$ & 0.60 & $<0.001$ & Moderate \\
\hline $\begin{array}{l}\text { Information provided at } \\
\text { pharmaceutical company- } \\
\text { sponsored CE events is balanced. }\end{array}$ & $\begin{array}{l}\text { My relationship to the industry } \\
\text { promotes my professionalism and } \\
\text { helps me care for my patients. }\end{array}$ & 0.36 & $<0.001$ & Moderate \\
\hline $\begin{array}{l}\text { Accepting small gifts from } \\
\text { pharmaceutical companies } \\
\text { influences my practice and how } \\
\text { I make drug recommendations. }\end{array}$ & $\begin{array}{l}\text { Accepting small gifts from } \\
\text { pharmaceutical companies influences } \\
\text { other pharmacists' practice and how } \\
\text { they make drug recommendations. }\end{array}$ & 0.69 & $<0.001$ & Moderate \\
\hline $\begin{array}{l}\text { Accepting large gifts from } \\
\text { pharmaceutical companies } \\
\text { influences my practice and how } \\
\text { I make drug recommendations. }\end{array}$ & $\begin{array}{l}\text { Accepting large gifts from } \\
\text { pharmaceutical companies influences } \\
\text { other pharmacists' practice and how } \\
\text { they make drug recommendations. }\end{array}$ & 0.77 & $<0.001$ & Strong \\
\hline
\end{tabular}

\section{DISCUSSION}

To the authors' knowledge, this is the only (and hence most comprehensive) assessment to date of Canadian hospital pharmacists' perceptions of the effects of their interactions with the pharmaceutical industry. The findings illustrate beliefs similar to those that have been reported for medical students. ${ }^{5,6,12}$ Nearly everyone in the current study cohort claimed some interaction with the pharmaceutical industry, and one-fifth to one-third perceived that those interactions influenced their behaviour and that of their colleagues.

Overall, these results indicate that most hospital pharmacists in the study area have attended industry-sponsored education events with or without meals, that most believe the information received at these events was unbalanced, and that most believe this information did not influence their practice or how they made therapeutic recommendations. Roughly a third of the study cohort held generally positive or neutral beliefs about the effects of their interactions with the pharmaceutical industry. Their beliefs about their own susceptibility to pharmaceutical industry influence were moderately and directionally correlated with their beliefs about the susceptibility of their colleagues. However, a minority of pharmacists (22\%) who believed themselves impervious to influence did not have the same belief about their colleagues. This phenomenon of discordance has previously been observed among other professionals, ${ }^{13}$ including physicians. ${ }^{14-17}$ Cognition research has also shown that when people are exposed to information and instructed to not let it influence their judgment, they are generally unable to do so. ${ }^{13}$ However, people generally underestimate the degree to which they are influenced and overestimate the degree to which others are influenced. ${ }^{12}$ These findings led us to believe that the respondents who held discordant beliefs about the effects of industry-sponsored continuing education may be exhibiting cognitive bias. If the consequences to patient care of being influenced by pharmaceutical industry-sponsored continuing education are negative, holding a fallacious belief about imperviousness to influence could be detrimental to patient care without the caregiver realizing it. However, respondents were not specifically asked whether the influence was negative or positive. It is possible that those who thought that they had been influenced were referring to a positive influence, which would not necessarily lead to negative effects on patient care. That a cognitive bias was at work here is suggested by the finding that none of the respondents held the opposite discordant belief that they were more susceptible to influence than their colleagues. Interestingly, this "imperviousness bias" was much less evident in relation to receipt of large or small gifts ( $6 \%$ and $4 \%$, respectively), about which respondents held more consistent beliefs.

A large proportion of the study cohort reported that they had, at some point in the past, accepted gifts from the pharmaceutical industry, most of them small. Respondents generally believed that they and their colleagues were not influenced by small gifts, but they were divided about the influence of large gifts. This belief about the importance of the size (i.e., value or relevance) of the gift concurs with research among medical students. A recent systematic review and other studies of the effects of pharmaceutical industry marketing on medical students have concluded that relatively inexpensive gifts were considered more appropriate than expensive gifts., ${ }^{5,14,18}$ Professional organizations have a role in guiding their members in terms of situations that may create a conflict of interest and pose ethically challenging scenarios. The American Society of Health-System Pharmacists (ASHP) suggests that members should not accept gifts that are meant to influence behaviour ${ }^{18}$ and should not accept "gifts of a 
personal nature". ${ }^{19}$ Canadian Society of Hospital Pharmacists (CSHP) guidelines state that members should not accept gifts of a personal nature and go on to say that donations may be accepted but should not influence decision-making. In our opinion, however, neither organization provides clear guidance for pharmacists to determine what types of gifts or donations may or may not actually influence them or what types of gifts could influence their decision-making. In addition, neither organization clearly defines gifts that would be considered as being of "a personal nature." On the basis of the results presented here, which suggest some uncertainty regarding the effects of interactions with the pharmaceutical industry, it may beneficial for ASHP and/or CSHP to provide more detailed guidance and to take a greater role in educating pharmacists about and creating awareness around the issues of interactions with the pharmaceutical industry. For example, these organizations could develop a series of webinars or educational events discussing what is known about the influence of gift-giving and personal biases, as well as what is known about influences on decision-making by professionals. In addition, these organizations could provide members with clear examples of the types of gifts and interactions that fall into the categories described in their guidelines (e.g., gifts known to influence, gifts of a personal nature, gifts that may influence decision-making). This type of information could be distributed easily to members during the process of membership renewal.

For the finding that many respondents had attended industry-sponsored continuing education events despite considering the information as unbalanced, at least 4 interpretations are possible. First, these respondents may believe that the influence of interactions with the pharmaceutical industry on their practice is positive or neutral (hence no conflict). Second, they may believe that the benefits (e.g., social interaction with colleagues, awareness of industry messages) of interactions with pharmaceutical industry outweigh potential undesirable effects. Third, they may have a "blind spot" and may not have considered (or may have been unwilling to admit in the survey) that these behaviours were at least potentially conflicting. Finally, they may not have engaged in personal reflection about these issues. Unfortunately, this study did not specifically assess the first and second possibilities, but the potential for positive effects deserves further study. For example, it is possible that pharmacists are prompted by receipt of information that they know to be biased to do self-directed research and thereby to develop a more comprehensive and accurate understanding of the therapeutic issues.

The third or "blind spot" possibility can be explained by several well-described cognitive biases. For example, "self-serving bias" ${ }^{\prime \prime}$ refers to the ability of individuals to justify their own actions, even if those actions put them in a position of conflict of interest or are logically or ethically questionable. The perception that any influence on themselves is less pronounced than influence on their peers may be explained by actor-observer asymmetry, ${ }^{20}$ choice-supportive bias, ${ }^{21}$ and the "introspection illusion", 22 all of which, in general terms, suggest that people generally perceive themselves to be less susceptible to influence and believe observations that support their own beliefs while ignoring observations that do not support those beliefs.

This study had several limitations. First, the response rate was relatively low, which raises the possibility of selection bias. An extremely broad spectrum of pharmacists across multiple large health authorities was surveyed, and the representativeness of the sample relative to all practising hospital pharmacists, as reflected in the cohort, is uncertain. For example, a disproportionately small number of very experienced pharmacists participated, so these results may not reflect the views of younger pharmacists. Also, participants who believed their actions put them in a conflict of interest were not asked whether they had changed their behaviours as a result, which could have led to overestimation of the degree of cognitive bias on their part. Observation of a sequence effect (i.e., attend event, perceive conflict, stop attending) could have mitigated the inferred biases, but this study was cross-sectional, not longitudinal, in nature. Also, when queried about industry interactions influencing their practice, respondents were not asked to specify the direction of such influence (e.g., beneficial versus undesirable), and the investigators' inference that it was mostly undesirable may have been inappropriate. Finally, the sequence of the questions, which was not randomized, may have been suggestive to some respondents, possibly influencing their responses.

Although there is no clear evidence that raising awareness about the effects of receiving biased information or the existence of cognitive biases reduces susceptibility to them, increased awareness may prompt some pharmacists to reduce their exposure to such influences. Indeed, "[b]ecause the brain cannot see itself fooling itself, the only reliable method for avoiding bias is to avoid the situations that produce it." ${ }^{13}$ As such, one of the implications of this research will be a campaign to share the survey results with respondents in an effort to increase awareness and stimulate discussion as it relates to interactions with the pharmaceutical industry. This campaign may lead to future research or prompt changes in individuals' beliefs or perceptions and could also prompt changes in individuals' behaviour as it relates to such interactions. We also plan to share the results with local policy-makers (i.e., those who create rules for how pharmacists interact with the pharmaceutical industry) in an effort to prompt discussion of the implications of these findings for current policies, with the ultimate goal of determining whether changes are necessary.

One other issue that requires discussion is the span of about 5 years that elapsed between data collection and study publication and how this interval might affect the relevance of these data to the current environment. We believe that the information 
from this study remains relevant because most of the interactions with the pharmaceutical industry discussed herein still occur (e.g., sponsored continuing education, small gifts). It could be argued that the pharmaceutical industry no longer distributes large gifts. Nonetheless, we felt that the perception of bias and influence related to past receipt of large gifts remains an interesting topic, one that has not previously been investigated among Canadian hospital pharmacists.

\section{CONCLUSIONS}

Most Canadian hospital pharmacists responding to this survey reported attending industry-sponsored events, and the majority felt that such attendance did not influence their clinical decision-making, despite recognition that the information received is unbalanced. It could also be said that these pharmacists did not feel that event attendance influenced their practice precisely because they perceived the information to be unbalanced. The survey did not ascertain the exact reasons for these perceptions, but both explanations are possible. Increased awareness of these findings among hospital pharmacists may prompt self-reflection and modification of behaviours and attitudes toward interactions with the pharmaceutical industry, which may in turn reduce the risks to patient care and professional integrity that can result.

\section{References}

1. Ziegler MG. The accuracy of drug information from pharmaceutical sales representatives. JAMA. 1995;273(16):1296-8.

2. Mintzes B, Lexchin J, Sutherland JM, Beaulieu MD, Wilkes MS, Durrieu $\mathrm{G}$, et al. Pharmaceutical sales representatives and patient safety: a comparative prospective study of information quality in Canada, France and the United States. J Gen Intern Med. 2013;28(10):1368-75.

3. Wazana AA. Physicians and the pharmaceutical industry: is a gift ever just a gift? JAMA. 2000;283(3):373-80.

4. Dana J, Loewenstein $\mathrm{G}$. A social science perspective on gifts to physicians from industry. JAMA. 2003;290(2):252-5.

5. Grande D, Frosch DL, Perkins AW, Kahn BE. Effect of exposure to small pharmaceutical promotional items on treatment preferences. Arch Intern Med. 2009;169(9):887-93.

6. Katz D, Caplan AL, Merz JF. All gifts large and small: toward an understanding of the ethics of pharmaceutical industry gift-giving. Am J Bioeth. 2010;10(10):11-7.

7. Morgan MA, Dana J, Loewenstein G, Zinberg S, Schulkin J. Interactions of doctors with the pharmaceutical industry. JMed Ethics. 2006;32(10):559-63.

8. Spurling GK, Mansfield PR, Montgomery BD, Lexchin J, Doust J, Othman $\mathrm{N}$, et al. Information from pharmaceutical companies and the quality, quantity, and cost of physicians' prescribing: a systematic review. PLoS Med. 2010;7(10):e1000352.

9. Burkiewicz JS, Zgarrick DP. Evidence-based practice by pharmacists: utilization and barriers. Ann Pharmacother. 2005;39(7-8):1214-9.

10. Farthing-Papineau EC, Peak AS. Pharmacists' perceptions of the pharmaceutical industry. Am J Health Syst Pharm. 2005;62(22):2401-9.

11. Gilovich T, Epley N, Hanko K. Shallow thoughts about the self: the automatic components of self-assessment. In: Alicke MD, Dunning DA, Krueger J, editors. The self in social judgment. Psychology Press; 2005. p. 77.
12. Austad KE, Avorn J, Kesselheim AS. Medical students' exposure to and attitudes about the pharmaceutical industry: a systematic review. PLoS Med. 2011;8(5):e1001037.

13. Gilbert D. I'm O.K., you're biased. The New York Times. 2006 Apr 16.

14. Steinman MA, Shlipak MG, McPhee SJ. Of principles and pens: attitudes and practices of medicine housestaff toward pharmaceutical industry promotions. Am J Med. 2001;110(7):551-7.

15. Chimonas S, Brennan TA, Rothman DJ. Physicians and drug representatives: exploring the dynamics of the relationship. J Gen Intern Med. 2007;22(2): 184-90.

16. Hodges B. Interactions with the pharmaceutical industry: experiences and attitudes of psychiatry residents, interns and clerks. CMAJ. 1995;153(5): 553-9.

17. Sierles FS, Brodkey AC, Cleary LM, McCurdy FA, Mintz M, Frank J, et al. Medical students' exposure to and attitudes about drug company interactions: a national survey. JAMA. 2005;294(9):1034-42.

18. ASHP guidelines on pharmacists' relationships with industry. Am J Hosp Pharm. 1992;49(1):154.

19. Pharmaceutical industry: guidelines for the relationship between healthcare facility pharmacists and the pharmaceutical industry. Ottawa $(\mathrm{ON})$ : Canadian Society of Hospital Pharmacists; 2001. 7 p.

20. Malle BF, Knobe JM, Nelson SE. Actor-observer asymmetries in explanations of behavior: new answers to an old question. J Pers Soc Psychol. 2007;93(4):491-514.

21. Mather M, Shafir E, Johnson MK. Misremembrance of options past: source monitoring and choice. Psychol Sci. 2000;11(2):132-8.

22. Pronin E, Kugler MB. Valuing thoughts, ignoring behavior: the introspection illusion as a source of the bias blind spot. J Exp Soc Psychol. 2007;43(4): 565-78.

Aaron M Tejani, BSc(Pharm), PharmD, is with the Pharmacy Department, Lower Mainland Pharmacy Services, and the Therapeutics Initiative, The University of British Columbia, Vancouver, British Columbia.

Peter Loewen, BSc(Pharm), PharmD, is with the Faculty of Pharmaceutical Sciences, The University of British Columbia, Vancouver, British Columbia.

Richard Bachand, BSc(Pharm), PharmD, is with the Pharmacy, Vancouver Island Health Authority, Victoria, British Columbia.

Curtis K Harder, BSc(Pharm), PharmD, is with the Pharmacy, Vancouver Island Health Authority, Victoria, British Columbia.

Competing interests: For work outside the scope of this study, Aaron Tejani has received a grant from the College of Pharmacists of British Columbia to conduct interprofessional education sessions; lecture honoraria from the REACH Primary Care Clinic (Vancouver), the Community and Rural Internal Medicine Society (British Columbia), BC Naturopathic Physicians, Vancouver Island Health Authority Pharmacy Services, and UBC Faculty of Medicine; and travel and accommodation expenses from Yellowknife Primary Care Physicians, Penticton RECC, and Kelowna Hospital. No other competing interests were declared.

\section{Address correspondence to:}

Dr Aaron M Tejani

Therapeutics Initiative

University of British Columbia

2176 Health Sciences Mall

Vancouver BC V6T 1 Z3

e-mail: aaron.tejani@ti.ubc.ca

Funding: None received. 